\title{
SANCTIONING CORPORATIONS
}

\author{
Meir Dan-Cohen*
}

\section{REFORMULATING THE QUESTION}

The question this symposium invites us to discuss, ought collective entities be criminally punished, arises in the intersection between two sets of issues, ontological and normative. In order to address this question, we must form some conception of what collective entities are; this is the ontological challenge. And we must form a conception of just or appropriate punishment; this is the normative challenge. We would probably not be here today if there were agreement on either of these matters, let alone if there were agreement on both. In fact, there is none. The question we address, though broadly discussed, remains highly contested. But though the question receives conflicting answers, there is one point of tacit agreement: that the question is properly posed. The very disagreement as to whether collectivities should be criminally punished attests to a shared premise that this question sets the correct scholarly agenda, and that a positive or negative answer is the desired goal. My starting point in this paper is to question the question. By presenting us with a binary option this question forces upon us a false dilemma that distorts the debate and induces unwarranted, sometimes paradoxical consequences. Refusing the question is the first step toward escaping the dilemma and rectifying the terms of the debate to which it gives rise.

Though the question in question concerns collectivities in general, like other participants in this symposium I focus for the

* Milo Reese Robbins Chair in Legal Ethics, University of California at Berkeley School of Law. I'd like to thank Robert Leider for his research assistance. This is an expanded version of a talk given on Feb. 5, 2010 at Brooklyn Law School's David G. Trager Public Policy Symposium on "Sharing the Blame: The Law and Morality of Punishing Collective Entities." 
most part on just one type of collectivity: the large corporation. ${ }^{1}$ (For the sake of brevity, from now on I omit the adjective.) This selectivity is not adventitious. First, corporations form a particularly salient and significant group of collective entities. Secondly, they share some characteristics that make them a distinctive and relatively homogenous type of collectivity. Corporations are formal and instrumental collectivities. Formal, in the sense that they have an elaborate and relatively well-defined organizational structure, and instrumental in the sense that their creation and maintenance is oriented toward the accomplishment of certain goals seen as providing the corporation with legitimacy and a raison d'être. ${ }^{2}$ My comments can be extended, with caution and necessary adjustments, to various other collectivities that resemble corporations in relevant respects. But though the following discussion may thus have wider implications, I consider directly only the narrower version of the question: should corporations be criminally punished? For ease of reference I label this the Question.

\section{A. Two Assumptions}

Two tacit assumptions regarding criminal punishment underlie the Question: that such punishment is, first, a unitary category which, secondly, derives its meaning from a paradigm case involving individual offenders. Call these, respectively, the assumption of unity and the assumption of individuality. The first assumption is implicit in the single label used to designate the practice under consideration. Only if this label stands for a singular, unified practice, can the Question be meaningfully posed. The second assumption is implicit in the challenge that

1 This designation combines the strictly legal notion of incorporation, i.e., being the bearer of legal rights and obligations, with the sociological notion of an organization, which connotes structure and a certain level of complexity.

${ }^{2}$ I distinguish corporations from other collectivities, most significantly from communities, and draw some normative implications of the distinction in, for example, Between Selves and Collectivities: Toward a Jurisprudence of Identity, 61 U. CHI. L. REV. 1213, 1216, 1232, 1239-40 (1994), and Freedoms of Collective Speech: A Theory of Protected Communications by Organizations, Communities, and the State, 79 CALIF. L. REV. 1229, 1230-31, 1244-58 (1991). 
collectivities supposedly present in this regard: punishing corporations is perceived as extending a practice whose natural domain is populated by individuals.

It is easy to see how these assumptions shape the debate. The first defines its conceptual contours. Whether or not to punish corporations is presented as a package-deal; we are asked to cast a yes-or-no vote, as it were, on a single option, that of subjecting corporations to an existing regime of criminal justice. The second assumption dictates the normative tenor of the discussion: in order to be punishable, corporations must be assimilated in one way or another to the paradigmatic individual offenders, and so the normative considerations and concerns that bear on punishing corporations turn out to be those that bear on punishing individuals. In light of these two assumptions, the dilemma to which I alluded is clear: punishing corporations requires forcing them, conceptually as well as normatively, into a pre-existing Procrustean bed designed to accommodate a different type of inhabitant; yet to refrain from punishing them is to exempt some powerful agents, capable of great social harm, from a significant instrument of social control.

\section{The Assumption of Unity}

When made explicit, both assumptions look shaky, and ways of loosening their grip appear. Consider the assumption of unity first. Criminal punishment consists of a variegated cluster of ideas and a complex institutional structure. It is not made of whole cloth. Nevertheless, treating it, with the aid of a single label, as an undifferentiated unit, has great practical as well as intellectual merit. Thinking, no less than practice, hinges on such composites whose unity is for the most part taken for granted. Yet depending on the goals we pursue or the nature of the investigation we conduct, it is sometimes advisable to disaggregate a given composite and refine the analysis by attending more closely to the composite's components. The legal treatment of corporations is a sufficiently fundamental matter to call for such an approach. Simply too much is at stake in this area for us to ignore the heterogeneity and complexity of what criminal punishment designates. 
Once we look at criminal punishment even through the feeblest magnifying glass and subject it to the dullest scalpel, many disparate elements spring into view and can be pried apart. Criminal punishment is a form of centralized social control that employs coercion, is initiated by the state, is rule-bound, is judicially administered, and so forth. Each of these elements can be in turn further unpacked: there is no algorithm for delimiting in advance the level of detail that would best serve in a thorough investigation of the kind the Question calls for. Judgment is required to decide how fine grained our approach ought to be. The Question, however, avoids such a judgment by hiding the multiplicity of issues and options that arise in this area under the terminological rug it blithely throws over them. When we peer under the rug or remove it entirely, we are in a better position to pick and choose among various elements in an effort to best adapt the practice of punishment as designed for individual offenders to the properties of the collectivities concerned.

\section{The Assumption of Individuality}

The effort to adjust criminal punishment to a corporate context is also hampered by the second assumption underlying the Question, the assumption of individuality. Conceiving of individuals as the paradigmatic criminal offenders implies an obvious criterion in light of which the Question must be answered: corporations are punishable if and only if punishing them would amount to or be the equivalent of punishing individual human beings. There are two ways in which this criterion can be satisfied in principle, and they correspond to the two main schools of thought regarding the nature of collectivities, the holistic and the reductionist. Roughly speaking, those I call holists affirm the existence of collective entities over and above, as the saying goes, their individual members. ${ }^{3}$ Reductionists, by contrast, maintain that

3 Holism, as used here, refers to a very large umbrella, under which a heterogeneous range of views congregate. As an indication of this range, it may be helpful to divide these views into three subcategories-call them the notional, the epistemological, and the metaphysical-differing in the level of "robustness" of the existence they claim for corporations, or, put differently, in the size or nature of the gap they posit between individual members and the 
to talk about collective entities is to use a shorthand or indulge in a fiction, and in either case is to designate nothing but the multitude of individual agents and their interactions. Though the holistic and the reductionist approaches to collectivities are, ontologically speaking, polar opposites, their normative implications can, perhaps somewhat surprisingly, converge. This is most likely to happen when the holistic approach assumes, sometimes unwittingly, an anthropomorphic mode. Whether the corporation is envisaged by the holist as an individual-like entity or by the reductionist as an aggregate of individuals, its legal treatment is assimilated to the treatment appropriate for individual human actors.

The inquiry concerning the punishment of corporations accordingly assumes one of two forms. Seen from the holistic perspective, the question is whether the collectivity as a whole is similar enough to an individual agent so as to make the imposition of punishment appropriate. Seen from the reductionist perspective, the question is whether the individual members of the corporation stand to the criminal actions ascribed to the corporation in a relationship that legitimates punishing them. By moving the investigation along either of these lines, the question whether corporations ought to be criminally punished loads the dice in favor of a negative answer. For the holists, advocating corporate punishment requires that they identify in the corporation relevant human properties that permit analogizing it to an individual; such

corporation. A notional view highlights the fact that a reified conception of the corporation is deeply entrenched in our ordinary language and practices and proceeds to ascribe normative significance to such entrenchment. An epistemological view highlights the complexity of the network of relationships constitutive of the corporation, maintaining that this creates an insurmountable cognitive barrier for any attempt to account for the corporate phenomenon in individual terms. This leaves open the possibility that such reduction is possible "in principle." The third, metaphysical view is distinguished by denying this last claim, insisting instead (on various and sometimes conflicting grounds) that corporations exhibit global properties that are not even in principle amenable to an individualist reduction. I ignore these distinctions for the most part, treating the holistic camp as unified, though a more thorough treatment of the issues involved would explore links between these subcategories and the specific arguments I make. 
theorists risk committing the notorious anthropomorphic fallacy. ${ }^{4}$ Reductionist advocates of corporate punishment find themselves on an equally treacherous path: they in effect favor the imposition of a form of collective punishment on a heterogeneous group of people many of whom do not satisfy the requirements of blameworthiness ordinarily required by criminal law. Attenuating these requirements in the present context seems both dangerous and ad hoc.

\section{B. Sanctions and Constraints}

In light of these daunting difficulties, it is no surprise that many theorists embrace the negative horn of the dilemma created by the Question, much as this position collides with a pre-theoretical reluctance to let corporations off the criminal hook. ${ }^{5}$ Others resist this conclusion, contriving instead an affirmative answer. ${ }^{6}$ However, these theorists too have been led astray by the Question and fallen into what may be a less visible, but no less perilous, trap. By resolving the dilemma in favor of corporate punishment, these theorists are likely to view themselves as striking a blow against corporate power and its abuses; they fashion themselves

${ }^{4}$ For illustrative discussions of warnings to this effect, see ROBERT B. REICH, SUPERCAPITALISM: THE TRANSFORMATION OF BUSINESS, DEMOCRACY, AND EVERYDAY LIFE 218-19 (2007); John C. Coffee, Jr., "No Soul to Damn: No Body to Kick": An Unscandalized Inquiry into the Problem of Corporate Punishment, 79 MICH. L. REV. 386, 386 n.2, 390, 441, 448 (1981).

5 See, e.g., John Hasnas, The Centenary of a Mistake: One Hundred Years of Corporate Criminal Liability, 46 AM. CRIM. L. REV. 1329 (2009); Joseph F. Francis, Criminal Responsibility of the Corporation, 18 ILL. L. REV. 305, 314 23 (1924); V.S. Khanna, Corporate Criminal Liability: What Purpose Does it Serve?, 109 HARV. L. REV. 1477 (1996); Eliezer Lederman, Criminal Law, Perpetrator and Corporation: Rethinking a Complex Triangle, 76 J. CRIM. L. \& Criminology 285 (1985); Manuel Velasquez, Debunking Corporate Moral Responsibility, 13 BUS. ETHICS Q. 531, 538-40 (2003); see also 1 WILLIAM BlaCKSTONE, COMMENTARIES *476-77.

${ }^{6}$ See, e.g., Lawrence Friedman, In Defense of Corporate Criminal Liability, 23 HARv. J. L. \& PUB. POL'Y 833 (2000); Regina A. Robson, Crime and Punishment: Rehabilitating Retribution as a Justification of Organizational Criminal Liability, 47 AM. Bus. L.J. 109 (2010); see also N.Y. Cent. \& Hudson River R.R. v. United States, 212 U.S. 481, 494-96 (1909). 
the black rather than the white knights of the corporate world. In fact, the blow they strike may have just the opposite effect.

To see this paradoxical aspect of the present debate we must return to the first assumption underlying the Question, concerning the supposed unity of punishment. In contesting this assumption, I have distinguished a number of disparate factors in the practice of punishment. But for present purposes a binary division is all we need. The most prominent and indeed a defining element in the practice of criminal punishment is the sanction, by which I mean the use of coercive power to affect conduct. But the practice of punishment has an additional salient aspect: an unusually restrictive system of constraints-substantive, procedural, and evidentiary - to which the use of coercion is subject. The debate concerning the punishment of corporations focuses on the first element, the sanction, whereas the second element, the constraints, is mostly taken for granted, and so remains invisible. An affirmative answer to the Question accordingly involves not only a recommendation that corporations be liable to sanction, but also a further and usually undefended implication that once the state imposes sanctions on a corporation, it is bound by the same network of constraints that tie its hands when punishing individuals. $^{7}$

Once we depart from the unitary notion of criminal punishment, and, specifically, distinguish between sanctions and constraints, the Question whether corporations ought to be criminally punished becomes bifurcated. First, ought corporations be sanctioned, that is subject to the coercive enforcement of criminal norms? Second, ought the sanctioning of corporations be bound by criminal law's strict constraints? In the next section I argue for an affirmative answer to the first question, and in the following section, for a negative answer to the second. In the final section I sketch some further implications of the view I advocate.

${ }^{7}$ With occasional exceptions; see, e.g., Doe v. United States, 487 U.S. 201, 206 (1988) (privilege against self-incrimination does not apply to corporations). 


\section{IN FAVOR OF SANCTIONS}

\section{A. A Theory of Punishment}

The two questions just distinguished can only be pursued in light of the answers we give to more preliminary ones that reach to the fundamentals of criminal law theory: Why does the criminal law impose sanctions? Why does it employ constraints? Though this is a highly contested area, I will proceed with an approach to punishment that enjoys considerable support. The justification of punishment on this account is an interplay between deterrence and retribution, and correspondingly, between a consequentialist, mostly utilitarian strand, and a deontological, mostly Kantian strand, each respectively answering one of the preliminary questions. According to this familiar story, criminal law's coercive threats are designed to promote some social goals or values. But these goals and values set necessary but insufficient conditions for imposing punishment. The reason is that we can imagine situations in which punishment would serve its legitimating purposes when imposed on someone who is innocent of any wrongdoing, ${ }^{8}$ and yet punishing the innocent even in those situations would be a moral outrage. But why? Seen in consequentialist terms, the answer is far from obvious; the opposition to punishing the innocent rests more securely on broadly Kantian grounds. Punishing the innocent, even in the service of some desirable goals, amounts to treating an individual as a means rather than as an end, in violation of the Categorical Imperative, and so is offensive to human dignity. ${ }^{9}$ The retributive aspect of punishment ensures that punishment be limited to the blameworthy, thereby adding a necessary moral permission to the consequentialist reasons that support coercion in

${ }^{8}$ This could be the case, for example, when punishment is imposed on the wrong person by mistake, or through deliberate framing. In either case, the deterrent efficacy of the sanction remains undiminished as long as people believe in the defendant's guilt.

${ }^{9}$ In the formulation most relevant here, the Categorical Imperative states: "Act in such a way that you always treat humanity, whether in your own person or in the person of any other, never simply as a means, but always at the same time as an end." IMMANUEL KANT, GROUNDWORK OF THE METAPHYSIC OF MORALS 91 (H. J. Paton trans., 1948). 
the first place. ${ }^{10}$

To be sure, the line between the two sets of reasons that bear on punishment-deterrence-related consequentialist goals and retribution-related deontological side-constraints-is not welldefined. The constraints consist primarily in the various elements of blameworthiness which substantive criminal law requires, and which evidentiary and procedural standards help safeguard. However, some level of wrongdoing, and thus arguably some form of blameworthiness, is implicit in the imperative of deterrence itself: random sanctions would make for a poor deterrent. The imperatives of deterrence therefore link sanctions to wrongdoing in ways that resemble the retributive side-constraints. But although the line between such "internal" limitations on sanctions on the one side and their extraneous, deontological constraints on the other is blurred, it is not obliterated, for two reasons. First, deterrence only requires an attenuated level of wrongdoing, arguably to the point of altogether dispensing with the subjective elements of crime, and correlatively with most of criminal law's defenses. ${ }^{11}$ Consequently, much, if not quite all, of what substantive criminal law demands by way of blameworthiness must be explained by appeal to

10 This account is sometimes referred to as the mixed or hybrid theory of punishment. See, e.g., Mitchell N. Berman, Punishment and Justification, 118 ETHICS 258, 258-59 (2008). An early, classical version is H. L. A. Hart, Prolegomenon to the Principles of Punishment, in 60 PROCEEDINGS OF THE ARISTOTELIAN SOCIETY 1 (1959-60). See also JefFrie G. MurPHY \& Jules L. COLEMAN, PHILOSOPHY OF LAW: AN INTRODUCTION TO JURISPRUDENCE 117-24 (rev. ed., Westview Press 1990) (1984). Seen in this way, punishment is a special case of what has become a pervasive liberal template, in which the normative test for various institutions and practices combines consequentialist and deontological elements: consequentialist considerations define the goal of the institution or the practice, but the pursuit of this goal is subject to deontological side-constraints, designed to safeguard individuals and their rights from being unjustly sacrificed on society's altar. The canonical texts are RONALD DWORKIN, TAKING RIGHTS SERIOUSLY (1977), especially chapters 4, 7, and 12, and ROBERT NOZICK, ANARCHY, STATE, AND UTOPIA 26-53 (1974). For an illuminating overview, see SAMUEL SCHEFfler, THE REJECTION OF CONSEQUENTIALISM (rev. ed. 1994) (1982). For a book-length study of the application of this template to various areas of law, see EYAL ZAMIR \& BARAK MEDINA, LAW, ECONOMICS, AND MORALITY (2010).

11 See, e.g., Richard A. Wasserstrom, Strict Liability in the Criminal Law, 12 STAN. L. REV. 731 (1960). 
considerations that go beyond the imperatives of deterrence and so amounts to external constraints. Second, evincing a heightened anxiety lest an innocent defendant be punished, the evidentiary and procedural strictures of the criminal trial amplify and fortify these substantive constraints by erecting on the road to conviction some formidable obstacles which exceed what pure consequentialist considerations would mandate. ${ }^{12}$

\section{B. Practical Personality}

How does this account of criminal punishment bear on corporations? It will facilitate the discussion if at the outset we distinguish between, on the one hand, the conditions an entity must satisfy to be a proper object of the consequentialist considerations that buttress sanctions, and on the other, the conditions for it to be an object of the deontological concerns that buttress the sideconstraints. To mark the distinction, I'll associate the former conditions with the possession of what I call practical personality, and the latter with the possession of moral personality. The distinction as drawn at this point is purely formal; it does not prejudice the inquiry as to what is the relationship between the two sets of conditions. Some writers in effect maintain that they overlap, or that one entails the other. ${ }^{13}$ I argue that they do not.

The notion of practical personality is designed to answer the question of whether applying sanctions to an entity makes sense. Specifically, it spells out the preconditions for using coercive power as a measure of control with respect to corporations. For

12 See, e.g., Herbert L. Packer, Two Models of the Criminal Process, 113 U. PA. L. REV. 1, 27 (1964) ("[People] have to be prepared to pay a price for a regime that fosters personal privacy and champions the dignity and inviolability of the individual. That price inevitably involves some sacrifice in efficiency ...."); see also Peter Arenella, Rethinking the Functions of Criminal Procedure: The Warren and Burger Courts' Competing Ideologies, 72 GEO. L.J. 185, 201-02 (1983) (noting the value of Fifth and Sixth Amendment protections apart from their contributions to producing efficient and accurate results in criminal trials); Richard B. Saphire, Specifying Due Process: Toward a More Responsive Approach to Procedural Protection, 127 U. PA. L. REV. 111, 117-25 (1978) (finding the dignity of the individual to be a basic value underlying the due process required by the Fifth and Fourteenth Amendments).

${ }^{13}$ See sources cited infra note 25 . 
such measures to be potentially effective, and so for the imposition of sanctions on the corporation to be sound, it must be possible to ascribe to the corporation as a whole, that is at a global, nondistributive level, (1) patterns of behavior and consequences, (2) that are amenable to change by means of the coercive measures employed. This in turn requires that we be able to ascribe to the corporation causal efficacy, displayed in such performances as manufacturing widgets or polluting the environment, as well as some cognitive faculties. These faculties must include some form of instrumental rationality, manifested as much in the harnessing of the corporation's causal powers to the pursuit of some goals, as in responsiveness to norms and to threats that back them up. For such threats to have a bite, all that is required in turn is that they involve representations of actions designed to thwart in one way or another the corporation's pursuit of its guiding goals, and so be perceived as a setback to what can be labeled the corporation's interests.

It is at least plausible to maintain that corporations display practical personality in this sense. Our ordinary ways of talking about corporations and a host of practices and attitudes regarding corporations take some such picture for granted. These ways of talking, practices, and attitudes find support in the kinds of considerations put forward by more systematic and reflective accounts of corporations within organization theory broadly conceived. Though this is not the place to canvass this extensive literature, its gist as it bears on the issue at hand can be briefly indicated.

Organization theorists characterize formal organizations most frequently by the presence of a decision-making process. The idea of decision making implies the capacity to perform such functions as gathering, registering, recording, decoding, and disseminating information. These information-related functions are generally imputed to the organization, rather than to specific individuals, because the total information that leads to a certain decision, action, or product is not normally possessed by any single individual, nor is it just the combined knowledge possessed by a number of identifiable individuals. Instead, what information is gathered, to whom it is disseminated, how it is decoded, and how it is combined and brought to bear on the final outcome critically depend on the structure of the organization, on the presence or 
absence of particular units or positions in it, and on the relevant standard operating procedures. ${ }^{14}$ Furthermore, in speaking of an organizational decision we presuppose the existence of some organizational preferences, which lend a certain unity and intelligibility to the pattern of events we think of as corporate behavior. Here, too, it is sensible to impute preferences to the organization itself, since its decisions need not be a direct reflection of any underlying pattern of individual preferences. For example, a coalition view depicts organizational decision making as a bargaining process among various groups with divergent and often conflicting interests. Decisions are accordingly characterized as the "political resultants"15 of these complex bargains, achieved in part by logrolling and strategic behavior. Social choice theory articulates more generally the obstacles, both practical and conceptual, to aggregating individual preferences into a collectively rational choice. ${ }^{16}$ Portraying organizations as "intentional systems" $"$ possessed of "organizational intelligence" 18 are cogent ways of expressing the view that organizations make decisions

14 See, for example, Robert H. Bonczek, Clyde W. Holsapple \& ANDREW B. Whinston, Foundations OF DECISION SUPPORT SYSTEMS (1981), for the role and nature of information processing in organizations.

${ }^{15}$ See Graham T. Allison, EsSence of Decision: Explaining THE CUBAN MISSILE CRISIS 162 (1971):

[R] esultants in the sense that what happens is not chosen as a solution to a problem but rather results from compromise, conflict, and confusion of officials with diverse interests and unequal influence; political in the sense that the activity from which decisions and actions emerge is best characterized as bargaining along regularized channels among individual members of the [organization].

${ }^{16}$ See, e.g., KenNeTh J. ARrow, Social Choice AND Individual Values 3-4 (John Wiley \& Sons, Inc., 2d ed. 1963) (1951); R. DUNCAN LUCE \& HowARD RAIFFA, GAMES AND DECISIONS 327-70 (1957); THOMAS SCHELlinG, Micromotives AND MACrobehavior (1978). See Philip Pettit, Responsibility Incorporated, 117 ETHICS 171, 180-84 (2007), for a recent version of this line of reasoning applied to the question of corporate personality.

17 See Daniel Dennett, Conditions of Personhood, in BRAINSTORMS: PHILOSOPHICAL ESSAYS ON MIND AND PSYCHOLOGY 267, 271 (1978) (defining intentional systems as systems or organisms whose behavior can be explained by reference to beliefs, desires, and intentions).

${ }^{18}$ See Harold L. WILENSKY, ORganizational INTELLIGENCE: KNOWLEDGE AND POLICY IN GOVERNMENT AND INDUSTRY (1967). 
infused with cognitive content, that are the product of widely dispersed informational sources and diffuse individual interests and attitudes, all mediated by structures, processes, and chance, in ways that defy translating or tracing the organizational decision into its individual sources. By thus spelling out the grounds for imputing global properties to organizations, the considerations I have sketched serve to reassure us that the ordinary reifying language we commonly apply to organizations need not depend on a metaphorical personification nor on some far-reaching metaphysical commitments. The position these considerations support can be instead summarized as holding that whereas a corporation is constituted by a bunch of individuals, it is not identical with them, since constitution, in this case, is not identity. ${ }^{19}$

\section{Why Sanction}

The notion of practical personality is designed to capture conditions that support sanctioning an entity exhibiting it. Thus the case just made for ascribing practical personality to corporations is ipso facto also a case for subjecting them to sanctions. Even so, and in light of the pervasiveness of a contrary view, it may be helpful to spell out the link between the corporation's practical personality and the argument for sanctions a bit more fully. This link consists in two complementary claims: that sanctioning corporations is potentially needed and that it is potentially efficacious. Both the need and the efficacy depend on a dual distinction, implicit in the notion of practical personality, between, first, distributive and non-distributive corporate acts, and correspondingly, between distributive and non-distributive effects on the corporation.

19 The difference between constitution and identity is most commonly illustrated by the alleged difference between a clay statue and the lump of clay of which it is made: for example, the statue can be destroyed without the lump of clay being destroyed. For a discussion of some of the issues involved in regard to the identity of material objects, see generally Lynne Rudder Baker, Why Constitution is Not Identity, 94 J. PHIL. 599 (1997). It probably goes without saying that this doctrine is contested in the case of material objects no less than in the case of corporations to which I extend it. 
By distributive acts I mean acts which, though ascribed to the corporation, are performed by some identifiable individuals; nondistributive acts are corporate acts which are not traceable or reducible to the acts of particular individuals. The word "identifiable" and the equivocation between traceable and reducible signify a difference between a weaker and a stronger interpretation of non-distributive acts. The stronger interpretation denies that a corporation's manufacturing widgets, or for that matter, polluting the environment, can in all cases be accounted for in terms of individual actions even in principle. The weaker interpretation points to the complexity and opacity of the corporation as posing a practical obstacle to tracing corporate acts to their individual constituents, rendering such tracing too costly or otherwise impracticable even if possible in theory. ${ }^{20}$ Similar remarks apply to the effects of actions putatively directed toward the corporation. Such actions will have distributive effects when the effects are traceable or reducible to some particular individuals, and non-distributive effects otherwise.

Non-distributive corporate acts indicate the need for enforcement measures addressed to the corporation, since they reveal a gap between controlling through punishment the conduct of particular individuals on the one hand, and a modification of the corporation's conduct on the other. Without sanctioning the corporation, we face therefore an accountability and enforcement deficit. But this is only half the case for sanctioning corporations. The fact that there is a gap does not mean that ways of filling it exist, and in particular that corporate sanctions would avail. The other half of the argument accordingly concerns the likely efficacy of imposing sanctions on the corporation.

Here the notion of non-distributive effects comes into play. Corporate sanctions are distinguished precisely by the fact that they are intended to have negative effects on the corporation as such, rather than on any particular individuals. How are such nondistributive effects on the corporation likely to modify its conduct?

In answering this question, it is helpful to distinguish three mechanisms of control that can be subsumed under the general heading of deterrence. I will call them respectively direct

${ }^{20}$ See supra note 3. 
deterrence, indirect deterrence, and mediated deterrence. Direct deterrence designates the most common, garden-variety form of deterrence in which the sanction is designed to influence the decisions and so directly modify the conduct of its intended object; the target of the sanction ${ }^{21}$ and the object of control coincide. In the two other forms of control, these diverge. Indirect deterrence occurs when, due to some special relationship between the target of sanction and the object of control, addressing a sanction to the one will influence the decisions of the other; for example, when the abduction of a politician by a radical group is designed to put pressure on the government, not on the captured politician. In mediated deterrence, the target of the sanction holds a position of power over the object of control or is otherwise able to modify the latter's behavior. Here, the sanction is intended to impact its immediate target, but only so as to induce actions that will in turn influence the ultimate object of control, such as when holding parents responsible for the misdeeds of their children is intended to induce parental control over the children's behavior.

Evidently, all three mechanisms of control have a grip in the case of corporations and can be expected to exert influence on their performance. Sanctioning the corporation involves direct deterrence when we envisage the sanction, in impersonal terms, as a "disturbing event" in the corporation's environment which serves to alert its decision making process to the existence of a certain dysfunction, triggering some standard operating procedure into taking remedial action consisting in some structural or systemic changes like modifying the communication network, introducing hitherto non-existent operations, etc. ${ }^{22}$

Additionally, and despite the non-distributive effects of corporate sanctions, both indirect and mediated deterrence provide viable strategies for influencing some (unidentified) individuals as a way of affecting corporate behavior. Indirect deterrence takes place when, whether out of loyalty or self-interest, members of the corporation respond to the harm to the corporation represented by

21 This refers to the entity to which the threat of sanction is directed and on which the sanction is actually imposed in case of breach.

22 This description draws particularly on the depiction of organizational behavior in RICHARD M. CYERT \& JAMES G. MARCH, A BEHAVIORAL THEORY OF THE FIRM (2d ed., Blackwell Publ'g Inc. 1992) (1963). 
sanctions. Their response may amount to or bring about a change in the corporation's behavior. Mediated deterrence reverses this direction of influence, which in this case runs from the corporation to its individual members. A corporation may react to sanctions by seeking to identify responsible individuals and take remedial action addressed to them. ${ }^{23}$

\section{AGAINST CONSTRAINTS}

\section{A. No Moral Personality}

But if corporations have practical personality, and so are amenable to sanctions, do they not have moral personality as well? The notion of moral personality as I use it here is specifically designed to capture the conditions by virtue of which the imposition of sanction ought to be subject to the criminal law's battery of constraints. On the conception of criminal punishment I have adumbrated, these constraints protect human dignity. To ask whether corporations have moral personality is accordingly to inquire whether the idea of human dignity extends to them. Though when posed in this way the question may seem absurd, a rather straightforward line of reasoning would seem to lead to a positive answer. And though no one I know defends explicitly ascribing dignity to corporations, ${ }^{24}$ some writers come close. Following a vaguely Kantian line, they assume that the kinds of properties I associate with practical personality-a capacity for unified action and for rational decision making-constitute people's moral personality as well. Once it is realized that corporations display these properties, they too must be recognized

${ }^{23}$ This mechanism of deterrence is particularly emphasized in BRENT FISSE \& John Braithwaite, Corporations, Crime and ACCountability 32-34 (1993).

${ }^{24}$ With perhaps one prominent exception, Jeremy Waldron, who has recently advocated ascribing dignity to collectivities of various kinds. See Jeremy Waldron, The Dignity of Groups, 2008 ACTA JuRIDICA 66, 74-90 (2008). But I am not sure that even he means to include business corporations. At any rate, his concept of dignity derives from the notion of high social rank, and so is quite different from the Kantian notion of dignity on which I rely. 
as moral persons. ${ }^{25}$ Those who pursue this line of reasoning are often concerned with securing a basis for holding corporations responsible for harms they inflict, but the implicit result is to credit them with dignity as well, thus unwittingly extending to them the cluster of rights and protections that this idea entails. ${ }^{26}$ Can we do better than that? Can we deny corporations the supreme moral worth that the idea of dignity designates, while holding them answerable for harmful acts? To explore this possibility we need take a closer look at the relationship between practical and moral personality. Does the one entail the other?

The negative answer I urge tackles what may appear as the most innocuous link in the chain of reasoning just outlined. It is an assumption not primarily about the ascription of moral personality to corporations, but more basically about the moral personality of human beings, to whom corporations are in turn compared. According to this assumption, unless the ascription to human beings of supreme moral worth is grounded in a suitable list of abstractly conceived characteristics, such ascription must be deemed arbitrary and self-serving, betraying merely a "traditional prejudice in favor of biological persons. ${ }^{, 27}$ From this it seems to follow that in order to provide human dignity with the supposedly requisite foundation, we must start by composing a list of characteristics that would provide rational support for attributing dignity to their bearers. The items I subsumed under the label of practical personality are plausible candidates for such a list. The crunch, however, is that once we follow this strategy and compose a schedule of dignity-conferring traits, it becomes an open question of fact which entities display these traits and answer to the

${ }^{25}$ For widely ranging variants of this theme, see, for example, T. Ozar, The Moral Responsibility of Corporations, in ETHICAL ISSUES IN BUSINESS: A PHILOSOPHICAL APPROACH 294, 294-99 (Thomas Donaldson \& Patricia Werhane eds., 1979), Thomas Donaldson, Moral Agency and Corporations, 10 PHIL. IN ConTEXT 54 (1980), Peter A. French, The Corporation as a Moral Person, 16 AM. PHIL. Q. 207 (1979), and Pettit, supra note 16.

${ }^{26}$ For a similar caveat, see Manuel G. Velasquez, Why Corporations are not Morally Responsible for Anything They Do, 2 BUS. \& PROF. ETHICs 1, 1-18 (1983).

27 Peter A. French, Collective AND Corporate Responsibility 34 (1984). 
description they constitute. Individual human beings by and large turn out to qualify (though some may not!), but in principle so can other entities, corporations included.

This line of reasoning, common though it is, has things in reverse. Practical personality, as I use this notion, is indeed a descriptive category. Whether an entity possesses it can be established by observation and study, even if what is being observed and studied is at bottom a cluster of human practices, discursive or otherwise. Ascribing to people moral personality, i.e., an unconditional and inviolable worth, is an altogether different idea. For those who adhere to it, it defines the core of their humanism and serves as their most fundamental normative premise; it is not the conclusion of a train of reasoning but its starting point. And insofar as human dignity is seen as the cornerstone or starting point of a normative system, it cannot be read off, and in this sense grounded in, a configuration of empirical facts. The moral worth of human beings is immune to an investigation into which entities possess some abstractly conceived dignity-conferring traits, since it is not in the first place the product of such an investigation. By the same token, it is not an open question whether entities other than human beings may be found to possess these traits. In particular, it is not as though staring long and hard at corporations and studying them with care might reveal them to have the supreme moral worth with which at least a liberal creed invests individual human beings. ${ }^{28}$ This kind of anthropomorphic fallacy would not be just a factual error, but would involve a category mistake. ${ }^{29}$

${ }^{28}$ Would intelligent Martians be potentially endowed with dignity? In contemplating such hypothetical possibilities, we imagine the Martians to be in effect human. What exactly "in effect" amounts to, however, need not be spelled out before the Martians land, and as long as human beings are the only candidates for moral personhood as here understood.

${ }^{29}$ Category mistakes occur when a person "represents the facts of mental life as if they belonged to one logical type or category (or range of types or categories), when they actually belong to another." GILBERT RYLE, THE CONCEPT OF MIND 16 (Univ. of Chicago Press 2000) (1949). The risk of committing the fallacy in the present context is vividly conveyed in the title, though not the content, of Susanna Kim Ripken's article, Corporations Are People Too: A Multi-Dimensional Approach to the Corporate Personhood Puzzle, 15 FordHAM J. CORP. \& FIN. L. 97 (2009). 
The mistake against which I inveigh is often committed in Kant's own name. Doesn't he hold that moral personality, and so dignity, issue from a capacity for autonomy, one that closely resembles practical personality as I use the term? And isn't this capacity an empirical trait, that some creatures display and others lack? We are of course not bound to follow Kant every step of the way, but it is important to raise a red flag against common aberrations that result from following him only part of it. In holding that autonomy grounds dignity, we should be careful to distinguish autonomy in Kant's own transcendental sense, from an empirical sense in which autonomy designates some observable human psychological capabilities, which though supposedly more advanced and sophisticated, are nonetheless of the same kind as those displayed by many other creatures, be it computers or giraffes. ${ }^{30}$ After all, one of the main points of the idiom of dignity as used by Kant is to deny that people's value can be placed in the same metric as the value of anything else. ${ }^{31}$ The role of human beings in a Kantian axiology is not in the first place as the objects of valuation but as its subjects, as the creators and origins of value. This is a complex idea to which we cannot hope to do justice in this space, but the crux of the matter may perhaps be stated as follows. The most distinctive human accomplishment is the creation of a world: the projection of a system of categories or meanings within which facts become intelligible and evaluative judgments possible. People's own supreme worth is not itself the product of this projection but its precondition. It is a necessary presupposition of the validity or objectivity that we claim for the normative orders we inhabit. This is the sense in which human beings are all the exclusive parties to a unitary and comprehensive system of meanings, members, in Kant's uplifting imagery, in the "Kingdom of Ends."

Once a system of categories, concepts, values and the like is in

30 See KANT, supra note 9.

31 Though Kant does talk about a seemingly broader category, of rational beings, people are the only terrestrial beings it comprises. See id.

${ }^{32}$ See id. at 95 . To be sure, the meanings are often contested, but crucially, the contestation is in principle always possible, underwritten by the unity and comprehensiveness of the system of meanings within which it takes place. Needless to say, Kant's universalism is itself highly contested. 
place, it makes room for, among many other things, human beings, seen as empirical objects of observation. And as the observation of human beings reveals, they do generally display the kinds of traits I've associated with the notion of practical personality, and so are the proper objects of control through sanction. But a crucial difference between their practical and moral personality remains. Practical personality is variable and contingent, whereas moral personality is unitary and categorical. People differ in their level of rationality and agency, and some display such capacities only marginally or not at all. Similar variation occurs intra-personally as well; the capacities in question fluctuate, and are occasionally extinguished, as during sleep or a coma. These variations impact the appropriateness of sanctions. But none of this affects the person's dignity and the respect it mandates. To be sure, the apposite manifestation of respect is sensitive to a person's state and capacities. For example, though respect ordinarily requires deference to a person's self-regarding choices, this requirement is moot in the case of someone who can't make any. But whatever the requisite manifestation of respect, the underlying value, dignity, is possessed by all human beings fully, equally, and uninterruptedly. ${ }^{33}$

The implications of this picture for the question at hand are clear. If deontological constraints in general, and those of the criminal law in particular, are tied to human dignity, the possibility that they should extend to corporations, seen as entities in their own right, is foreclosed from the start. ${ }^{34}$ Moreover, this conclusion is consistent with ascribing to the corporation, on the basis of observation and study, a practical personality, sufficient to justify

${ }^{33}$ It may be felt that tying the notion of moral personality to the possession of dignity commits us to an overly individualistic moral outlook. But how individualistic the outlook is depends on the conception of human beings we espouse, and in particular on the role of various collective affiliations in fixing their identities. Exploring the difficult issues that this raises lies outside the present topic.

34 This does not suggest, of course, that the government's power over corporations is unlimited. The point is only that such limitations as do apply must have a consequentialist, perhaps utilitarian basis, and at any rate cannot be extended wholesale and as a matter of course from the individual-oriented arrangements of ordinary criminal law. 
the sanctioning of corporations in order to enforce desirable norms of conduct and improve corporate performance.

\section{B. Effects on Members}

But even if corporations are not identical with or reducible to the aggregate of their individual members, sanctioning corporations will have predictably negative effects on their members, whether shareholders or other stakeholders. Does not sanctioning the corporation amount to sanctioning the members as well, thus reinstating on the members' behalf the need for the battery of side-constraints that punishing individuals requires? True, the nominal defendant in a corporate criminal trial is the corporation, rather than any designated individuals. But isn't ignoring the individual ramifications of the sanction to take this formality way too seriously, and to ascribe to the corporate veil magical powers?

To respond to these worries, we need to place them within a wider context by probing a bit further our earlier account of punishment. We saw that the imposition of sanctions threatens human dignity, and so calls for a particularly stringent battery of constraints. But why exactly is this the case? What precisely is it about criminal sanctions that provokes this anxiety and this response? A simple answer fixes on the obvious: criminal sanctions involve severe deprivations of people and a serious setback to their interests. Unless justified in a way consonant with the defendants' moral standing as ends in themselves, such deprivations are morally reprehensible. But a moment's reflection reveals the inadequacy of this simple answer. Two puzzles are particularly relevant. First, many other governmental practicestaxation, civil damages, military conscription, and fiscal policyoften involve similar deprivations, and yet none of them is as morally traumatic as the practice of punishment, nor are they restricted by a corresponding armory of constraints. The second puzzle concerns the way the effects of the sanctions themselves are assessed. Punishment frequently has negative ramifications that go beyond the particular defendant, impacting, sometimes severely, the defendant's family and others. Nevertheless, the law draws a sharp line between the effects of punishment on the defendant and 
its effects on other parties. While going to extraordinary length to safeguard that the defendant is indeed guilty of the crime charged, the law condones with near equanimity any indirect harm to other innocent parties.

\section{The Argument from Stigma}

If the simple answer does not adequately explain the special solicitude toward criminal sanctions, what does? I consider two alternatives. According to the first, a distinguishing mark of criminal punishment is its link to moral turpitude and so to stigma. ${ }^{35}$ The main point of criminal law's special safeguards is accordingly to protect individuals against an unwarranted stigmatization, and so against a particularly invidious insult to their dignity. If sound, this answer solves both puzzles: it explains the greater moral concern with punishment over other modes of governmental deprivation which do not carry such invidious implications, as well as the almost exclusive focus on the sanction's effects on the defendant. This answer also upholds the conclusion that sanctioning corporations need not be attended by criminal law's usual constraints, since it involves the stigmatization of no particular individual, and so threatens no one's dignity.

The argument from stigma seems to me right as far as it goes, but for our purposes it does not go far enough, for two reasons. First, not all criminal punishment need involve stigma. For example, it is at least debatable whether all mala prohibita offenses stigmatize. And governments may seek to enforce unjustifiable norms whose violation need not be associated with moral turpitude of any kind. Yet surely such employments of criminal sanctions do not exempt their users from the strictures that bind them in the case of more paradigmatic crimes. Second, for present purposes, the answer under consideration focuses on the wrong aspect of the

${ }^{35}$ See, e.g., Joel FeINBERG, The Expressive Function of Punishment, in DOING AND DESERVING: ESSAYS IN THE THEORY OF RESPONSIBILITY 95, 98 (1970); Sanford H. Kadish, Some Observations on the Use of Criminal Sanctions in Enforcing Economic Regulations, 30 U. CHI. L. REV. 423, 437 (1963) ("The central distinguishing aspect of the criminal sanction appears to be the stigmatization of the morally culpable."). 
criminal trial. Strictly speaking, the sanction itself does not stigmatize. Stigma attaches to the defendant by virtue of the conviction, the official pronouncement of guilt. If stigma were the main concern, it would appear that criminal law's constraints would remain unaffected even in the absence of any sanction following conviction. At least within the present understanding of criminal law, this is not a plausible conclusion to reach.

\section{The Argument from Mistreatment}

These considerations require that we move beyond stigma, and consider a second alternative. Since stigma depends on the content of the norms whose alleged violation is the basis for the sanction, in moving beyond stigma we must detach the special moral concern raised by criminal sanctions from the norms which the sanctions are designed to enforce. The aim is to reveal some formal characteristics of criminal sanctions that explain their special moral significance and so the constraints to which they are subject. My suggestion is that punishment is an instance of a kind of deprivation I call mistreatment, and that deprivations of this kind carry a particularly heavy moral weight. By mistreatment I mean $a$ deliberate singling out of an individual for the sake of a severe deprivation. ${ }^{36}$ In the remainder of this section I clarify and substantiate three claims: that criminal sanctions ordinarily exhibit these characteristics to a high degree; that this accounts for the law's special solicitude and the rigid constraints; and that sanctioning corporations, though likely resulting in some deprivations being inflicted on individuals, does not involve these individuals' mistreatment, and so ought to be exempt from the constraints.

It is easy to see that unlike other deprivations wrought by government action, criminal punishment presents an unambiguous

${ }^{36}$ All the elements in this definition are continua and can come in various versions and in different degrees. In particular, one can "single out" in the relevant sense a group of individuals, when one targets an identity-fixing, e.g., ethnic or racial, property common to its members. It is significant therefore that membership in a corporation (as, say, that of its shareholders) is not identityfixing, nor is the membership defined in terms of some other identity-fixing characteristic. 
case of mistreatment. The deleterious effects of a fiscal policy on employment, for example, can be accidental and unforeseen, whereas the deprivation involved in punishment is the product of a prolonged process of deliberation. Unlike taxation, which usually affects anonymous groups of individuals in an impersonal way, punishment focuses on a particular defendant, singling her out for a severe deprivation. Unlike quarantine, which may in principle be conducted in a five-star hotel, deprivation is the acknowledged purpose of punishment, not just a regrettable side-effect. Finally, criminal punishment involves particularly harsh deprivations. In noting this last feature, it is also noteworthy how this harshness is commonly assessed. The perception that punishment involves severe deprivations does not depend on its aggregate but rather on its distributive effects. If we were to assess the harshness of capital punishment, for instance, in aggregate terms and rank it among the various causes of death, it would probably not be of such great social and political moment; the number of people who actually die by execution is, statistically speaking, quite small. This fact does not, however, diminish our concern with capital punishment, since we deem it the most severe deprivation imposed on a particular individual. Here too there is a contrast with the way other forms of governmental deprivation are evaluated, e.g., the increase in road fatalities when, say, the speed limit is raised.

But why does it matter that punishment fits my definition of mistreatment? Why do the various elements conjoined in this notion cohere, aggravating the negative moral significance of a deprivation that exhibits them? Start by noting that this combination of factors is not unique to criminal punishment, and so is not ad hoc; rather, these factors characterize serious criminal offenses as well. Consider first-degree murder. Its heinousness is based in the first place on the judgment that it involves the infliction of a most grievous deprivation. Note also that this judgment looks exclusively at the effects on the victim. In placing murder above, say, robbery, and at the top of the severity list, we do not take into account the incidence of the two crimes to determine which is more socially harmful in the aggregate; we compare only the two felonies' distributive effects. Furthermore, the murderer targets an individual victim, whose death must be the offender's conscious objective rather than just a foreseeable side- 
effect of her action; and the action must be the product of "premeditation and deliberation," which marks it as more reprehensible than, say, reckless killing. In short, first-degree murder (and to a varying degree other core crimes) is an instance of mistreatment; our moral intuitions and the law's attitude are aligned with the factors I have listed. Why?

The answer I propose links up with the Kantian themes I pursued before. Morality, and correspondingly criminal law, insist that our behavior express due respect for each person's supreme moral worth. ${ }^{37}$ The various elements of mistreatment provide criteria for judging the extent to which behavior fails to be respectful of the other and instead conveys reprehensible disregard. By inflicting a severe deprivation on a particular individual one exhibits a lack of respect for her. By judging the severity of the deprivation exclusively in terms of the effects on the victim rather than in aggregate societal terms we signal our commitment to the unique value of the individual and her incomparable worth. ${ }^{38}$ Making the destruction of the other's interests one's affirmative goal is the epitome of disrespect: one enacts a conception of the victim as a mere means, someone whose own rights and interests can be trampled at will. ${ }^{39}$ And by doing all of this deliberately, one

${ }^{37}$ Cf. Thomas Nagel, War and Massacre, 1 PHIL. \& PuB. AfF. 123, 133 (1972):

The view that it can be wrong to consider merely the overall effect of one's actions on the general welfare comes into prominence when those actions involve relations with others. A man's acts usually affect more people than he deals with directly, and those effects must naturally be considered in his decisions. But if there are special principles governing the manner in which he should treat people, that will require special attention to the particular persons toward whom the act is directed, rather than just to its total effect.

${ }^{38}$ In stark contrast with utilitarianism's summation of effects on individuals, out of a concern for the sum total of such effects. See, e.g., CHARLES FRIED, RIGHT AND WRONG 33-34 (1978); JOHN RAWLS, A THEORY OF JUSTICE 22-27 (1971).

39 The distinction between the intended results and the unintended sideeffects of one's actions has a long pedigree in Western moral philosophy, leading back to the Catholic doctrine of double effect. See, e.g., T.A. Cavanaugh, Double-EFFect Reasoning: DoIng GoOd and Avoiding EviL (2006); The Doctrine of Double EfFect: Philosophers Debate A 
invests one's actions with their full negative meaning, leaving no room for doubt about the disrespectful attitude they convey. ${ }^{40}$

As these comments suggest, the formal characteristics of criminal sanctions parallel the formal characteristics of crime. Deliberately singling out a particular individual for the sake of inflicting on her a severe deprivation is a grave moral matter. Classifying sanctions as a case of mistreatment thus helps us appreciate the moral anxiety they produce. This account provides a straightforward answer to the puzzles regarding punishment we have raised, concerning the law's greater solicitude toward criminal sanctions compared to other forms of government generated deprivations, and the law's radically different attitude toward the sanction's effects on the defendant as against its effects on other parties. Being a form of mistreatment, criminal sanctions pose a greater threat to human dignity than other deprivations, and the person whose dignity is thus at stake is the defendant on whom the sanction is visited, not anyone else. The battery of constraints created by criminal law is designed to mitigate this threat by ensuring, as much as possible, that the defendant is justly treated rather than being the victim of the equivalent of a crime. ${ }^{41}$

Controversial Moral Principle (P.A. Woodward ed., 2001).

${ }^{40}$ The interpretation of first degree murder, and by extension of other core criminal offenses, as instances of mistreatment, implies that blameworthiness is here intrinsic to what the law aims to prevent, and not just an external constraint. See generally Benjamin B. Sendor, Crime as Communication: An Interpretive Theory of the Insanity Defense and the Mental Elements of Crime, 74 GEO. L.J. 1371 (1986). This suggests an additional fault line within criminal law as presently practiced (a fault line roughly corresponding to the distinction between mala in se and mala prohibita offenses) which separates offenses rooted in a moral concern to secure human dignity from those rooted in the imperatives of governance in a modern society. That a given level of blameworthiness is intrinsic to the wrong sought to be prevented by core offenses does not however entail that the same level of blameworthiness must be required for conviction: for purposes of deterrence, the law may cast a wider net. So even here, refraining from doing so, and insisting on a robust requirement of guilt, represents considerations associated with deontological constraints.

${ }^{41}$ Courts are sometimes required to decide whether a form of government deprivation not explicitly labeled as punishment is in fact punitive and so subject to criminal law's strictures. For example, in concluding that the revocation of citizenship is indeed punitive, the criteria enumerated by the Supreme Court include: 
The remaining step to our destination is short. Punishing the corporation involves no one's mistreatment. None of the shareholders or other stakeholders who are made worse off by the corporate sanction is personally singled out for a deliberate deprivation. Consequently, the effects of corporate sanctions on shareholders and other individuals do not carry the invidious message of disrespect that mistreating them would have. For this reason, the corporate veil not only hides but morally shelters individuals from the effects of corporate punishment. The resulting individual deprivations must, of course, be taken into account in designing the system of corporate criminal liability. But the role that these side-effects should play in our deliberations lacks the special urgency present when the mistreatment of individuals is at stake.

\section{FURTHER IMPLICATIONS}

Nothing I have said in this paper bears on the desirable level of government control of corporate behavior or on the best means of exercising such control. I have made two related, but different points. One is that the corporation is a suitable object for the

[w] hether the sanction involves an affirmative disability or restraint, whether it has historically been regarded as a punishment, whether it comes into play only on a finding of scienter, whether its operation will promote the traditional aims of punishment-retribution and deterrence, whether the behavior to which it applies is already a crime, whether an alternative purpose to which it may rationally be connected is assignable for it ....

Kennedy v. Mendoza-Martinez, 372 U.S. 144, 168-69 (1963). (For a slight variation of these criteria, see Kansas v. Hendricks, 521 U.S. 346, 361-63 (1997)). Some of the Court's criteria correspond to elements in my notion of mistreatment. Where the two sets of criteria diverge, some doubts about the Court's criteria come to mind, e.g., whether the deprivation has historically been regarded as a punishment appears uninformative (why was it so regarded in the first place?), and whether it comes into play only on a finding of scienter has things backward (if it is punitive it better be based on a finding of scienter, rather than the other way round). In any case, the notion of mistreatment gives the determination of punitiveness a unified theoretical basis in a way that the Court's criteria do not. 
imposition of sanctions. ${ }^{42}$ Second, insofar as the imposition of sanctions is deemed desirable, it need not be hampered by the same constraints as those that tie the government's hands when dealing directly with individuals. This dual conclusion has wider repercussions, within criminal law and beyond. Let me end by briefly indicating what they are.

The further repercussion relating to criminal law was foreshadowed earlier in the paper when I mentioned various ways other than the distinction between sanction and constraint in which criminal law can be disaggregated. This implies potentially additional ways in which the treatment of corporations within what we broadly conceive as the criminal law can be custom tailored to suit them in distinction from the treatment due to individuals. Exploring these possibilities might eventually lead to a two-track system, with the tracks differing along the substantive, procedural, and evidentiary dimensions. These tracks need not, however, end at the boundary of criminal law. The considerations that shape them pertain to other legal areas as well, suggesting a two-track legal system throughout. ${ }^{43}$ Though some steps in this direction have already been taken, they are spotty and sporadic. ${ }^{44}$ The present climate of heightened awareness toward corporations and their social role perhaps offers an opportunity for a more openminded and resolute willingness to rethink the law's attitude toward them across the board, and contemplate the intellectual and

42 This does not of course tell us when, if ever, the imposition of sanctions is warranted, or how it compares with other strategies of control.

${ }^{43}$ For an early precursor of a line of thought pointing in this general direction, see generally CHRISTOPHER D. STONE, WHERE THE LAW ENDS: THE SOCIAL CONTROL OF CoRPorate BEHAVIOR (1975).

${ }^{44}$ For example, numerous laws tie various special obligations to corporate size. See, e.g., Family and Medical Leave Act of 1993, 29 U.S.C.A. $§ \S 2601-$ 2654 (West 2010) (tying the right to take a leave of absence to care for certain family members to employees of corporations with fifty or more employees); Civil Rights Act of 1964, 42 U.S.C.A. $\$ 2000$ e (West 2009) (limiting the Act's prohibition on employment discrimination to companies that employ fifteen or more employees); $c f$. Sarbanes-Oxley Act of 2002, Pub. L. No. 107-204, 116 Stat. 745 (West 2010) (codified as amended in scattered sections of 15 U.S.C.) (imposing disclosure and auditing requirements upon publicly traded corporations). 
institutional transformations that might be required. ${ }^{45}$

Finally, the considerations canvassed in this paper stand for an even broader claim, that the corporate economy opens up an area in which the government has greater moral leeway than when its coercive power is brought to bear directly on individuals. Interposing an intermediate entity between the government and its citizens blunts some of the moral edge of coercion and mitigates the threat it otherwise poses to individuals' dignity and their autonomy. This has two complementary implications. One is that in dealing with corporations, the government may legitimately pursue social goals more aggressively than when dealing with individuals. ${ }^{46}$ The second implication is that the greater moral license the government enjoys in regard to corporations may bolster the government's circumspection in regard to individuals. The underlying suggestion is that whenever feasible, and other things being equal, ${ }^{47}$ the government shift its coercive powers from individuals to corporations, letting the latter serve as the preferred vehicles for attaining its policy objectives. Shifting in this way the brunt of government action from individuals to corporations may provide a way of promoting the social interest with a reduced moral toll.

${ }^{45}$ However, the suggested approach has recently suffered a severe setback in Citizens United v. Fed. Election Comm'n, 130 S. Ct. 876, 912-13 (2010), in which the Supreme Court reversed previous decisions that had limited corporate First Amendment protections. I address some of these broader issues in MEIR Dan-Cohen, Rights, Persons, and Organizations: A Legal Theory for BUREAUCRATIC SOCIETY (1986).

${ }^{46}$ But here again, moral license is one thing; sound policy that is consonant with it is another. How active the government should be in its dealings with corporations and what forms that activity should take are distinctly policy matters which lie entirely outside my present discussion.

${ }^{47}$ Which of course they never are; so this proposal is put forward not as a program for action, but as food for reflection. 
